\title{
Central venous-to-arterial carbon dioxide difference as a prognostic tool in high-risk surgical patients
}

Emmanuel Robin ${ }^{1 *}$, Emmanuel Futier $^{2}$, Oscar Pires ${ }^{1}$, Maher Fleyfel ${ }^{1}$, Benoit Tavernier ${ }^{1}$, Gilles Lebuffe ${ }^{1}$ and Benoit Vallet ${ }^{1}$

\begin{abstract}
Introduction: The purpose of this study was to evaluate the clinical relevance of high values of central venous-toarterial carbon dioxide difference ( $\mathrm{PCO}_{2}$ gap) in high-risk surgical patients admitted to a postoperative ICU. We hypothesized that $\mathrm{PCO}_{2}$ gap could serve as a useful tool to identify patients still requiring hemodynamic optimization at ICU admission.
\end{abstract}

Methods: One hundred and fifteen patients were included in this prospective single-center observational study during a 1-year period. High-risk surgical inclusion criteria were adapted from Schoemaker and colleagues. Demographic and biological data, $\mathrm{PCO}_{2}$ gap, central venous oxygen saturation, lactate level and postoperative complications were recorded for all patients at ICU admission, and 6 hours and 12 hours after admission.

Results: A total of 78 (68\%) patients developed postoperative complications, of whom 54 (47\%) developed organ failure. From admission to 12 hours after admission, there was a significant difference in mean $\mathrm{PCO}_{2}$ gap $(8.7 \pm 2.8 \mathrm{mmHg}$ versus $5.1 \pm 2.6 \mathrm{mmHg} ; P=0.001)$ and median lactate values $(1.54(1.1-3.2) \mathrm{mmol} / \mathrm{l}$ versus $1.06(0.8-1.8) \mathrm{mmol} / ; ; P=0.003)$ between patients who developed postoperative complications and those who did not. These differences were maximal at admission to the ICU. At ICU admission, the area under the receiver operating characteristic curve for occurrence of postoperative complications was 0.86 for the $\mathrm{PCO}_{2}$ gap compared to Sequential Organ Failure Assessment score (0.82), Simplified Acute Physiology Score II score (0.67), and lactate level (0.67). The threshold value for $\mathrm{PCO}_{2}$ gap was $5.8 \mathrm{mmHg}$. Multivariate analysis showed that only a high $\mathrm{PCO}_{2}$ gap and a high Sequential Organ Failure Assessment score were independently associated with the occurrence of postoperative complications. A high $\mathrm{PCO}_{2}$ gap $(\geq 6 \mathrm{mmHg})$ was associated with more organ failure, an increase in duration of mechanical ventilation and length of hospital stay.

Conclusion: $\mathrm{A}$ high $\mathrm{PCO}_{2}$ gap at admission in the postoperative ICU was significantly associated with increased postoperative complications in high-risk surgical patients. If the increase in $\mathrm{PCO}_{2}$ gap is secondary to tissue hypoperfusion then the $\mathrm{PCO}_{2}$ gap might be a useful tool complementary to central venous oxygen saturation as a therapeutic target.

\section{Introduction}

There is increasing evidence that individually optimized hemodynamic therapy oriented on goals to maintain and improve tissue perfusion and/or oxygenation improves patient outcome [1]. The development of tissue hypoxia is a leading cause of postoperative organ failure and mortality following major surgery [2,3]. Early recognition and correction of warning signals of persistent inadequacy of

\footnotetext{
* Correspondence: emmanuel.robin@chru-lille.fr

${ }^{1}$ Department of Anaesthesiology and Intensive Care Medicine, University Hospital of Lille, Lille, France

Full list of author information is available at the end of the article
}

tissue perfusion is therefore of particular importance, especially in patients with a reduced physiological reserve $[1,4]$.

The inability to meet an increase in oxygen $\left(\mathrm{O}_{2}\right)$ demand with surgical trauma either by an increase in $\mathrm{O}_{2}$ delivery or an increase in $\mathrm{O}_{2}$ extraction can lead to tissue hypoxia $[5,6]$. Several markers of impaired tissue oxygenation have been explored to help identify patients at increased risk of complications. Postoperative organ failure has been shown to be associated with reduced central venous $\mathrm{O}_{2}$ saturation $\left(\mathrm{ScrO}_{2}\right)$, which explores the balance of $\mathrm{O}_{2}$ delivery and tissue $\mathrm{O}_{2}$ consumption [7]. However, there is evidence that $\mathrm{O}_{2}$-derived variables are poorly correlated with anaerobic 
metabolism [8-11]. Indeed, both normal and high values (that is, $\geq 75 \%$ ) for $\mathrm{ScvO}_{2}$ do not preclude the presence of tissue hypoxia in case of impaired $\mathrm{O}_{2}$ extraction capabilities, which may therefore limit the usefulness of $\mathrm{ScvO}_{2}$ monitoring [12,13]. In contrast, it has also been shown that strategies aimed at reducing high serum lactate levels, as a warning signal of a persistent tissue hypoxia at ICU admission, could reduce length of stay and mortality [14,15]. However, a rise in lactate level may be delayed compared with markers of tissue oxygenation adequacy, such as oxygen extraction [16], and could be not sensitive enough to reflect tissue hypoperfusion [14].

Previous relatively small studies have proposed central venous-to-arterial carbon dioxide gradient $\left(\mathrm{PCO}_{2}\right.$ gap), a global index of tissue perfusion, as a useful measurement to characterize the insufficient flow state in spite of apparently normal macrocirculatory parameters $[17,18]$. Tissue partial pressure of carbon dioxide $\left(\mathrm{PCO}_{2}\right)$ reflects metabolic alterations due to inadequate perfusion in actively metabolized tissues [19]. The $\mathrm{PCO}_{2}$ gap, which has been shown to be inversely related to cardiac output (CO) [20], is considered as a marker of the ability of the venous blood flow to remove the $\mathrm{CO}_{2}$ excess produced in tissues [21]. Thus, an impaired tissue perfusion during a reduced blood flow is the main determinant of a rise of the $\mathrm{PCO}_{2}$ gap [22]. However, despite promising findings from both experimental and clinical data, the prognostic significance of the $\mathrm{PCO}_{2}$ gap has only been examined to a small extent in the context of major surgical trauma. The purpose of this study was to evaluate the clinical relevance of high values of the $\mathrm{PCO}_{2}$ gap, and their relationships to other markers of impaired tissue perfusion and oxygenation (that is, blood lactate and $\mathrm{ScrO}_{2}$ ). We hypothesized that the $\mathrm{PCO}_{2}$ gap could serve as a useful tool to help identify patients at high risk of postoperative complications at ICU admission following major surgery.

\section{Methods}

\section{Patients}

This was a prospective single-center observational study of patients scheduled for major abdominal and vascular surgery and admitted to the ICU of a University Hospital over a 1-year period. The study was approved by local Research Ethics Committee of the University Hospital of Lille, France, which permitted anonymous data analysis. The requirement for written inform consent was waived due to the strict observational design of this study.

Inclusion criteria adapted from Schoemaker and colleagues [23] are summarized in Table 1 and are divided into demographic, surgical and intensive care criteria. All patients undergoing abdominal or vascular surgery were included if they had one of the following criteria: 1 ) one demographic criterion and one surgical criterion; 2)
Table 1 Demographic, surgical and intensive care inclusion criteria

\begin{tabular}{|c|c|}
\hline High-risk criteria & Values \\
\hline \multicolumn{2}{|l|}{ Demographic criteria } \\
\hline Age $\geq 70$ years & $42(37)$ \\
\hline ASA class $\geq 3$ & $70(61)$ \\
\hline Severe nutritional problems & $11(10)$ \\
\hline Previous severe respiratory illness & $24(11)$ \\
\hline Chronic renal failure & $6(5)$ \\
\hline Chronic liver failure & $7(6)$ \\
\hline Ischemic heart disease (infarction or angina) & $51(44)$ \\
\hline Malignant neoplasia & $67(58)$ \\
\hline \multicolumn{2}{|l|}{ Surgical criteria } \\
\hline Major abdominal surgery & $82(71)$ \\
\hline Prolonged surgery $\geq 8$ hours & $9(8)$ \\
\hline Urgent surgery & $22(19)$ \\
\hline Septic surgery & $24(21)$ \\
\hline Vascular clamping $\geq 1$ hour & $4(4)$ \\
\hline \multicolumn{2}{|l|}{ Surgical procedures } \\
\hline Esophagectomy & $22(19)$ \\
\hline Gastrectomy & $9(8)$ \\
\hline Small bowel resection & $17(15)$ \\
\hline Large bowel resection & $20(17)$ \\
\hline Hepatectomy & $21(18)$ \\
\hline Pancreatectomy & $16(14)$ \\
\hline Intra-abdominal vascular surgery & $24(21)$ \\
\hline Other & $2(2)$ \\
\hline \multicolumn{2}{|l|}{ Intensive care criteria } \\
\hline Shock & $38(33)$ \\
\hline Acute respiratory failure & $32(28)$ \\
\hline Hemorrhage (hemoglobin <7 g/dl) & $10(9)$ \\
\hline Acute coronary syndrome & $7(6)$ \\
\hline
\end{tabular}

Data are presented as absolute value (\%). Severe nutritional problems: body mass index $\leq 17 \mathrm{~kg} / \mathrm{m}^{2}$ or weight loss $>10 \%$ in 6 months. Chronic renal failure: creatinine clearance $<60 \mathrm{ml} / \mathrm{min}$ per $1.73 \mathrm{~m}^{2}$ or creatinine $>176 \mu \mathrm{mol} / \mathrm{l}$. Chronic liver failure: bilirubin $>78 \mu \mathrm{mol} / \mathrm{l}$ or prothrombin time $<55 \%$ or well-documented cirrhosis. ASA, American Society of Anesthesiology physical status.

three or more demographic criteria; 3 ) three or more surgical criteria; 4 ) one intensive care criterion.

\section{Study protocol}

As part of our routine hemodynamic monitoring during major surgery, all patients were monitored with central venous (standard two-lumen catheter, Arrow, Wayne, Pennsylvania, USA; or PreSep catheter with oximetry, Edwards Lifesciences, Irvine, California, USA) and arterial (Seldicath, Plastimed, Le Plessis Bouchard, France) catheters placed before the beginning of surgery. The central venous line was positioned with the tip within the superior 
vena cava, and correct positioning was verified by chest radiograph. Until admission to the ICU, anesthesia and surgical procedures were performed according to the local standards. No specific hemodynamic protocol was used during surgery. All patients were admitted to the ICU immediately after surgery and were all managed according to our local standards of care.

\section{Data collection and outcome measures}

Standard postoperative monitoring included: electrocardiograph (heart rate), invasive mean arterial pressure, pulse oxymetry and urine output. In all patients, the $\mathrm{PCO}_{2}$ gap, calculated as the difference between central venous partial pressure of carbon dioxide and arterial partial pressure of carbon dioxide, $\mathrm{ScvO}_{2}$, serum lactate level, blood gas analysis, troponin I and routine laboratory tests were obtained by intermittent blood sampling immediately after admission (H0) and repeated $6(\mathrm{H} 6)$ and 12 hours (H12) later. At ICU admission, data on demographics (age, sex, weight), type of surgical procedure, American Society of Anesthesiology Physical Status score, Simplified Acute Physiology Score (SAPS) II [24], presence of catecholamine and the need for mechanical ventilation were recorded in all patients. Postoperative organ failure was assessed using the Sequential Organ Failure Assessment (SOFA) score recorded daily until ICU discharge.

Briefly, the organ failure criteria are:

- Circulatory failure: use of catecholamine to maintain a mean arterial pressure $\geq 65 \mathrm{mmHg}$ after a suitable fluid loading.

- Acute respiratory failure: need for mechanical ventilation or noninvasive ventilation.

- Acute kidney injury: 1.5-times increase in creatinine serum level or increased creatinine $>0.3 \mathrm{mg} / \mathrm{dl}$ or urine output $<0.5 \mathrm{ml} / \mathrm{kg}$ per hour for 6 hours.

- Neurological impairment: stroke with focal deficit or coma (Glasgow score $\leq 8$ ) or delirium.

Postoperative complications were assessed in accordance with previously defined criteria $[25,26]$ until hospital discharge or death as follows: postoperative sepsis (pneumonia, intraperitoneal abscess, wound infection, peritonitis and urinary tract infection), acute respiratory failure, acute renal and cardiac failures, postoperative hemorrhage, ischemic events, and postoperative mortality. Patients were followed-up until hospital discharge or death.

\section{Statistical analysis}

The study population was divided into two groups according to the occurrence of postoperative complications. Normal distribution of all variables was accessed by graphical methods and the Kolmogorov-Smirnov test. All data are presented as absolute value (\%), as mean \pm standard deviation or as median (interquartile range) when necessary. Differences between the two groups at baseline were analyzed using the Student's $t$ test or Mann-Whitney $U$ test for continuous variables, and chi-square test or Fisher's exact test for categorical variables. A repeatedmeasure analysis of variance was used to compare variables over time. When the sphericity assumption has been violated as assessed by Mauchly's test, the degrees of freedom were corrected using Greenhouse-Geisser estimates of sphericity. A Bonferroni correction was used for post hoc tests. Univariate analysis was performed to test associations with postoperative complications. A logistic regression was performed for multivariate analysis for all univariate relevant covariates that discriminate between the two groups ( $P$ value $<0.05$ was set as the limit for inclusion). A hierarchical entry method in two blocks was used. In the first block, variables usually known to influence prognosis were entered. In the second block, all other variables were entered. Receiver operating characteristic (ROC) curves were generated to identify optimal cut-off values for outcome associations, and the area under the ROC curve, sensitivity and specificity were calculated. The optimal threshold value from the ROC curves was assessed to obtain the highest Youden index and positive likelihood ratio. A $P$ value less than 0.05 was considered statistically significant. Statistical analysis was performed using the SPSS 17.0 software (Chicago, IL, USA).

\section{Results}

Between May 2008 and May 2009, 115 patients who fulfilled the entry criteria were included in the study. Baseline characteristics of the study population are given in Table 1. The median American Society of Anesthesiology Physical Status score was 3.0 (2.0-3.0), mean age was $65 \pm 12$ years, and $75 \%$ were male. At the time of inclusion (T0), the median SAPS II score was 19.5 (15.0-28.7) and the mean $\mathrm{ScvO}_{2}$ and $\mathrm{PCO}_{2}$ gap were $77.3 \pm 6.3 \%$ and $7.2 \pm 3.3 \mathrm{mmHg}$, respectively. A total of $43 \%$ of patients were mechanically ventilated, and $36 \%$ received catecholamine infusion. The median duration of mechanical ventilation was $0.0(0.0-3.0)$ days. The SOFA scores were 4.0 (1.0-10.0), 4.0 (1.0-8.0), and 4.0 (1.0-8.0) at postoperative days 1,2 and 3 , respectively. The median ICU and hospital length of stays were $6.0(4.0-8.0)$ days and 21.0 (15.0-29.0) days, respectively. The 28-day mortality rate was $8 \%$ (septic shock, $\mathrm{n}=4$; acute mesenteric ischemia, $\mathrm{n}=2$; myocardial infarction, $\mathrm{n}=2$; massive acute blood loss, $\mathrm{n}=1$ ).

\section{Association with outcome}

A total of $78(68 \%)$ patients developed postoperative complications during their ICU stay, of whom 57 (50\%) patients developed postoperative sepsis and 54 (47\%) patients developed organ failure (Table 2). At the time of 
Table 2 Postoperative complications

\begin{tabular}{ll}
\hline Variables & \\
\hline Sepsis & $57(49.6)$ \\
Pneumonia & $37(32.2)$ \\
Peritonitis & $17(14.8)$ \\
Wound infection & $2(1.7)$ \\
Urinary tract infection & $1(0.8)$ \\
Acute renal failure & $18(15.7)$ \\
Acute cardiac failure & $10(8.7)$ \\
Acute myocardial infarction & $5(6.1)$ \\
Pulmonary embolism & $3(2.6)$ \\
Hemorrhage & $14(12.2)$ \\
Lower limb ischemia & $11(9.6)$ \\
\hline
\end{tabular}

Data are presented as absolute values (\%).

surgery, patients with postoperative complications were more likely to undergo urgent surgery (Table 3 ). There were no other statistically significant differences in baseline high-risk criteria between the two patient groups. Patients with postoperative complications were more severely ill on ICU admission (SOFA score: 7.0 (3.0-12.0) versus 1.0 (1.0-2.5), $P<0.001$; SAPS II score: 23.0 (16.5-31.2) versus 15.5 (12.0-24.2), $P=0.008)$, had longer durations of mechanical ventilation (2.0 (0.0-3.0) days versus 0.0 (0.0-0.0) days, $P<0.001)$ and longer durations of hospital stay (25.0 (20.0-34.0) days versus $14.0(12.0-160), P<0.001)$. On the day of ICU admission, there were statistically significant differences in lactate level $(P=0.006)$, but not in $\mathrm{ScvO}_{2}$ values $(P=0.17)$ between patients who did and did not develop postoperative complications. Univariate analysis identified nine variables on ICU admission associated with the occurrence of postoperative complications on ICU admission: lactate level $(P=0.006)$, troponin level $(P=0.025)$, bicarbonate level $(P=0.008)$, arterial $\mathrm{O}_{2}$ saturation $(P=0.026)$, urine output $(P=0.023)$, $\mathrm{PCO}_{2}$ gap value $(P<0.001)$, SAPS II $(P=0.008)$, SOFA score $(P<0.001)$ and emergency surgery $(P=0.04)$. Multivariate analysis showed that a high $\mathrm{PCO}_{2}$ gap (odds ratio $=1.93,95 \%$ confidence interval $(\mathrm{CI}) 1.36$ to $2.75, P<0.001$ ) and a high SOFA score (odds ratio $=1.52$ $95 \% \mathrm{CI} 1.14$ to $2.02, P=0.004$ ) at $\mathrm{H} 0$ were independently associated with the occurrence of postoperative complications (Table 4). The same results were observed at $\mathrm{H} 6$ (data not shown). The area under the ROC curve for the occurrence of postoperative complications was 0.86 (95\% CI 0.77 to 0.95 ) for the $\mathrm{PCO}_{2}$ gap. The area under the ROC curve for organ failure for SOFA score, SAPS II score, lactate level and troponin value were $0.82,0.67,0.67$ and 0.57 , respectively (Figure 1). The optimal $\mathrm{PCO}_{2}$ gap value on ICU admission was $5.8 \mathrm{mmHg}$ (sensitivity $90.7 \%$, specificity $70.0 \%$, positive predictive value $86.6 \%$, and negative predictive value $78.8 \%$ ) for discriminating between patients who did and patients who did not develop postoperative complications. Of the 54 patients who developed organ failure, 46 had a $\mathrm{PCO}_{2}$ gap $\geq 6 \mathrm{mmHg}$. A high $\mathrm{PCO}_{2}$ gap $(>6 \mathrm{mmHg})$ was observed in $68 \%$ of the patients upon admission to the ICU after surgery. Compared with patients with a low $\mathrm{PCO}_{2}$ gap on ICU admission, a high $\mathrm{PCO}_{2}$ gap was associated with more organ failure $(P<0.001)$, and an increase in duration of mechanical ventilation $(P=0.002)$ and length of hospital stay $(P<0.001)$ (Table 5). In addition, a high $\mathrm{PCO}_{2}$ gap was associated with a higher 28 -day mortality rate ( $11.5 \%$ versus $0 \%, P=0.056)$.

\section{Trends in $\mathrm{PCO}_{2}$ gap}

Changes in the $\mathrm{PCO}_{2}$ gap and lactate values during the first 12 hours are shown in Figure 2. From H0 to H12, there was a significant difference for mean $\mathrm{PCO}_{2}$ gap $(P=$ $0.001)$ and mean lactate values $(P=0.003)$ between patients who did or did not develop postoperative complications. Maximal difference was present immediately after inclusion just after surgery $(8.7 \pm 2.8 \mathrm{mmHg}$ versus $5.1 \pm$ $2.6 \mathrm{mmHg}, P<0.001)$. There was a trend towards a decreased $\mathrm{PCO}_{2}$ gap all along the first 12 hours of medical support in the ICU for patients with postoperative complications $(P=0.064)$. Similar trends were present for the lactate level. There was also a significant difference for mean $\mathrm{PCO}_{2}$ gap $(P=0.003)$ between patients who developed organ failure and those who did not (Figure 3).

\section{Discussion}

The main finding of our study is that a $\mathrm{PCO}_{2}$ gap $>6 \mathrm{mmHg}$ at ICU admission following major surgery is predictive of postoperative complications in high-risk surgical patients. Patients with an enlarged $\mathrm{PCO}_{2}$ gap had more organ failure, increased durations of mechanical ventilation as well as length of hospital stay, and a trend towards higher mortality rates, although the latter did not reach statistical significance.

To the best our knowledge, this study is the first to evidence the prognostic significance of an enlarged $\mathrm{PCO}_{2}$ gap at ICU admission in high-risk surgical patients. In patients who developed postoperative complications, the increase in $\mathrm{PCO}_{2}$ gap was maximal immediately after ICU admission and gradually decreased thereafter as a result of medical support. The diagnostic performance of the $\mathrm{PCO}_{2}$ gap is quite similar to the SOFA score with the huge advantage of being measurable at patient admission. In addition, the measurement of the $\mathrm{PCO}_{2}$ gap is much more responsive than the SOFA score and easy to implement at the bedside. These results are supported by the results of a previous study by our group in which an enlarged $\mathrm{PCO}_{2}$ gap was associated with an increased rate of postoperative complications in patients who remained inadequately managed by volume loading during an individualized 
Table 3 Baseline characteristics of patients who did and did not develop postoperative complications

\begin{tabular}{|c|c|c|c|}
\hline Variables & $\begin{array}{l}\text { Patients with postoperative complications } \\
(\mathrm{n}=78)\end{array}$ & $\begin{array}{l}\text { Patients without postoperative complications } \\
(\mathrm{n}=37)\end{array}$ & $P$ value \\
\hline \multicolumn{4}{|l|}{ Severity scores } \\
\hline ASA class & $3.0(2.0-3.0)$ & $3.0(2.0-3.0)$ & 0.16 \\
\hline ASA class $\geq 3(\%)$ & $51(65)$ & $19(51)$ & 0.150 \\
\hline SOFA & $7.0(3.0-12.0)$ & $1.0(1.0-2.5)$ & $<0.001$ \\
\hline SAPS $\|$ & $23.0(16.5-31.2)$ & $15.5(12.0-24.2)$ & 0.008 \\
\hline \multicolumn{4}{|l|}{ High-risk criteria (\%) } \\
\hline Age, years & $64 \pm 13$ & $65 \pm 10$ & 0.84 \\
\hline Age $\geq 70$ years & $30(38)$ & $12(32)$ & 0.53 \\
\hline Severe nutritional problems & $8(10)$ & $3(8)$ & 1.00 \\
\hline Previous respiratory illness & $20(26)$ & $4(11)$ & 0.07 \\
\hline Chronic renal failure & $5(6)$ & $1(3)$ & 0.66 \\
\hline Chronic liver failure & $6(8)$ & $1(3)$ & 0.43 \\
\hline Ischemic heart disease & $32(41)$ & $19(51)$ & 0.30 \\
\hline Malignant neoplasia & $46(59)$ & $21(57)$ & 0.82 \\
\hline Major abdominal surgery & $52(67)$ & $30(81)$ & 0.11 \\
\hline Prolonged surgery $\geq 8$ hours & $6(8)$ & $3(8)$ & 1.00 \\
\hline Urgent surgery & $19(24)$ & $3(8)$ & 0.04 \\
\hline Septic surgery & $19(24)$ & $5(13)$ & 0.18 \\
\hline Vascular clamping $\geq 1$ hour & $4(5)$ & $0(0)$ & 0.30 \\
\hline \multicolumn{4}{|l|}{ Physiological parameters } \\
\hline Mean arterial pressure, $\mathrm{mmHg}$ & $82 \pm 16$ & $85 \pm 14$ & 0.30 \\
\hline Urine output, $\mathrm{ml} / 3$ hours & $266 \pm 228$ & $345 \pm 258$ & 0.023 \\
\hline \multicolumn{4}{|l|}{ Biologic parameters } \\
\hline Serum lactate, mmol/l & $1.54(1.1-3.2)$ & $1.06 \pm(0.8-1.8)$ & 0.006 \\
\hline Serum bicarbonate, $\mathrm{mmol} / \mathrm{l}$ & $19.6 \pm 4.2$ & $21.4 \pm 2.7$ & 0.008 \\
\hline Hemoglobin, g/dl & $10.4 \pm 1.8$ & $10.8 \pm 1.7$ & 0.39 \\
\hline Troponin I, ng/ml & $0.03(0.01-0.11)$ & $0.01(0.00-0.04)$ & 0.025 \\
\hline Arterial pH & $7.33 \pm 0.08$ & $7.35 \pm 0.07$ & 0.47 \\
\hline Venous pH & $7.28 \pm 0.09$ & $7.30 \pm 0.06$ & 0.06 \\
\hline $\mathrm{PCO}_{2}$ gap, mmHg & $8.7 \pm 2.8$ & $5.1 \pm 2.6$ & $<0.001$ \\
\hline $\mathrm{PcvCO}_{2}, \mathrm{mmHg}$ & $46.1 \pm 6.7$ & $45.9 \pm 6.0$ & 0.92 \\
\hline $\mathrm{PaCO}_{2}, \mathrm{mmHg}$ & $37.4 \pm 6.5$ & $40.7 \pm 6.2$ & 0.09 \\
\hline $\mathrm{ScvO}_{2}, \%$ & $76.3 \pm 6.3$ & $78.0 \pm 5.2$ & 0.17 \\
\hline $\mathrm{SaO}_{2}, \%$ & $99.2(98.4-99.5)$ & $98.8(98.1-99.2)$ & 0.026 \\
\hline $\mathrm{PaO}_{2}, \mathrm{mmHg}$ & $145(116-175)$ & $135(110-156)$ & 0.05 \\
\hline $\mathrm{PcVO}_{2}, \mathrm{mmHg}$ & $46.0(41.7-54.0)$ & $48,0(40.5-52.0)$ & 0.77 \\
\hline
\end{tabular}

Data are presented as absolute values (\%), mean \pm standard deviation, or median (interquartile range). Comparison between groups were assessed by Student's $t$ test or Mann-Whitney $U$ test when necessary. Significant $P$ values are indicated in bold text. ASA, American Society of Anesthesiology physiological status; PaCO ${ }_{2}$, arterial partial pressure of carbon dioxide; $\mathrm{PaO}_{2}$, arterial partial pressure of oxygen; $\mathrm{PCO}_{2}$ gap, central venous-to-arterial carbon dioxide gradient; $\mathrm{Pcv} C \mathrm{O}_{2}$, central venous partial pressure of carbon dioxide; $\mathrm{PcvO}_{2}$, central venous partial pressure of oxygen; $\mathrm{SaO}_{2}$, arterial oxygen saturation; SAPS, Simplified Acute Physiology Score; SOFA, Sequential Organ Failure Assessment; $\mathrm{ScvO}_{2}$, central venous oxygen saturation.

goal-directed therapy [17]. These results also echo those of previous studies in patients with severe sepsis or septic shock in which a large $\mathrm{PCO}_{2}$ gap was associated with higher rates of organ failure and greater mortality
[18,21,27]. In all these studies, the thresholds for $\mathrm{PCO}_{2}$ gap values were around 5 to $6 \mathrm{mmHg}$, as in our study.

The increase in venous $\mathrm{PCO}_{2}$ would reflect a state of insufficient flow relative to $\mathrm{CO}_{2}$ production $[28,29]$. Indeed, 
Table 4 Logistic regression results: variables associated with the occurrence of postoperative complications

\begin{tabular}{|c|c|c|c|c|}
\hline & $\mathrm{B}(\mathrm{SE})$ & Odds ratio & 95\% confidence interval & $P$ \\
\hline Constant & $-5.61(3.50)$ & & & \\
\hline $\mathrm{PCO}_{2}$ gap & $0.66(0.18)$ & 1.93 & $1.36-2.75$ & $<0.001$ \\
\hline SOFA score & $0.42(0.15)$ & 1.52 & $1.14-2.02$ & 0.004 \\
\hline Lactate & $0.38(0.37)$ & 1.47 & $0.71-3.02$ & 0.300 \\
\hline SAPS II score & $0.04(0.04)$ & 1.04 & $0.96-1.13$ & 0.347 \\
\hline Emergency surgery & $0.09(1.17)$ & 1.10 & $0.11-10.80$ & 0.937 \\
\hline Bicarbonate & $-0.07(0.11)$ & 0.931 & $0.75-1.16$ & 0.931 \\
\hline Troponin & $1.87(1.47)$ & 6.50 & $0.36-117.06$ & 0.204 \\
\hline diuresis & $0.0003(0.002)$ & 1.00 & $0.997-1.003$ & 0.825 \\
\hline
\end{tabular}

Model $X^{2}=54.96, P<0.001, R^{2}=0.50$ (Hosmer and Lemeshow), $R^{2}=0.48$ (Cox and Snell), $R^{2}=0.66$ (Nagelkerke). Significant $P$ values are indicated in bold text. $\mathrm{PCO}_{2}$ gap, central venous-to-arterial difference in carbon dioxide; SAPS II, Simplified Acute Physiology Score II; SE, standard error; SOFA, Sequential Organ Failure Assessment.

in an in situ, vascularly isolated, innervated dog hindlimb model, Vallet and colleagues evidenced that the $\mathrm{PCO}_{2}$ gap increased during low blood flow-induced tissue hypoxia (ischemic hypoxia) while it remained unchanged during hypoxemia-induced hypoxia (hypoxic hypoxia) [22]. These results were confirmed in a mathematical analysis model [30] and in in vivo conditions in pig [31] and in sheep [9]. These results are also in agreement with those of Bakker and colleagues [21] who showed that, in patients with septic shock, the $\mathrm{PCO}_{2}$ gap was smaller in survivors than in non-survivors, despite quite similar $\mathrm{CO}, \mathrm{O}_{2}$ delivery $\left(\mathrm{DO}_{2}\right)$ and $\mathrm{O}_{2}$ consumption $\left(\mathrm{VO}_{2}\right)$ values. In septic shock patients, characterized by an increased $\mathrm{PCO}_{2}$ gap and a low flow state, fluid challenge was found to lower the $\mathrm{PCO}_{2}$ gap while increasing $\mathrm{CO}$ [32]. In contrast, no

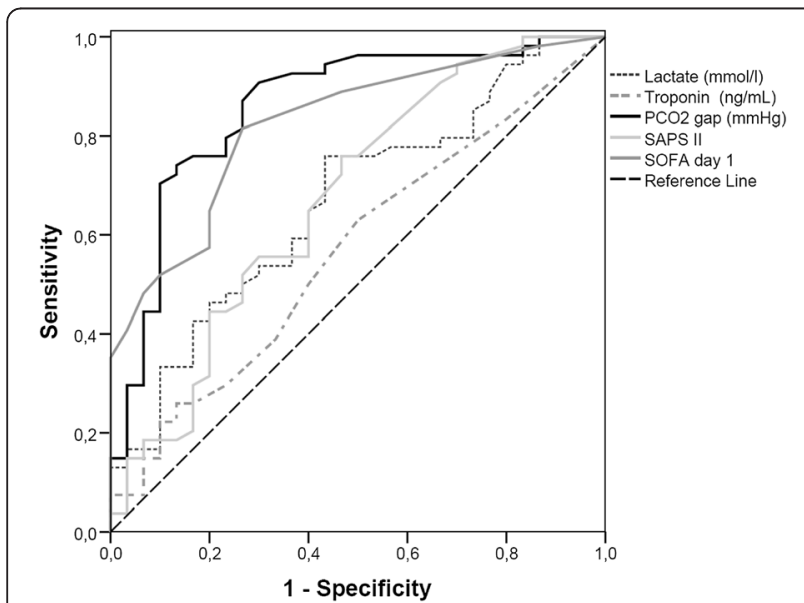

Figure 1 Discriminant factors of postoperative complications. Receiver operating characteristic curve comparing the ability of central venous-to-arterial difference in carbon dioxide ( $\mathrm{PCO}_{2}$ gap), Sequential Organ Failure Assessment (SOFA) score, Simplified Acute Physiology Score (SAPS) II score, lactate level and troponin level at baseline to discriminate between patients who did $(n=78)$ and did not $(n=37)$ develop postoperative complications. Areas under the curve are $0.86 ; 0.82 ; 0.67 ; 0.67$ and 0.57 , respectively. significant changes in $\mathrm{CO}$ and $\mathrm{PCO}_{2}$ gap were found in patients with normal $\mathrm{PCO}_{2}$, thus confirming the relationship between an increased $\mathrm{PCO}_{2}$ gap and insufficient flow [32].

In our study, $\mathrm{ScvO}_{2}$ did not allow us to discriminate between patients with and without postoperative complications. These results seem to contradict previous studies. Indeed, recently published data clearly demonstrate that low $\mathrm{ScvO}_{2}$ during and after major abdominal surgery is associated with an increased risk of postoperative complications $[7,16,33]$. In addition, $\mathrm{ScvO}_{2}$ was part of early goal-directed therapy protocol algorithms that have proven their effectiveness in improving the prognosis of patients [16,34]. As the use of $\mathrm{ScvO}_{2}$ has become increasingly popular in the management of high-risk surgical patients, one part of our patients (at the convenience of the anesthetist in charge of the patient) had already been treated using $\mathrm{ScvO}_{2}$ during surgery before inclusion in the study. The hemodynamics of our patients were in part optimized, as evidenced by $\mathrm{ScvO}_{2}$ values above $70 \%$ in both groups. Another point to consider is that sepsis was the main cause of postoperative complications in our study (47\%). In this situation where microcirculation failure is frequent, a normal

Table 5 Outcome of patients with high and low values of $\mathrm{PCO}_{2}$ gap on ICU admission

\begin{tabular}{llll}
\hline Variables & $\begin{array}{l}\text { PCO2 gap } \\
\mathbf{6} \mathbf{~ m ~ m H g} \\
(\mathbf{n}=\mathbf{7 8})\end{array}$ & $\begin{array}{l}\text { PCO2 gap } \\
<\mathbf{6 ~} \mathbf{~ m H g} \\
(\mathbf{n}=\mathbf{3 7})\end{array}$ & P value \\
\hline Total duration of MV, days & $2.0(0.0-3.2)$ & $0.0(0.0-0.0)$ & $<\mathbf{0 . 0 0 1}$ \\
Length of ICU stay, days & $6.0(4.0-8.2)$ & $5.0(4.0-7.5)$ & 0.287 \\
Length of hospital stay, days & $22.5(17.0-32.2)$ & $16.0(13.0-23.5)$ & $\mathbf{0 . 0 0 2}$ \\
Organ failure & $46(59.0 \%)$ & $8(21.6 \%)$ & $<\mathbf{0 . 0 0 1}$ \\
28-day mortality & $9(11.5 \%)$ & 0 & 0.056 \\
\hline
\end{tabular}

Areas under the curve are $0.86 ; 0.82 ; 0.67 ; 0.67$ and 0.57 , respectively. Data are presented as medians (interquartile range) or absolute value (\%). Significant $P$ values are indicated in bold text. $\mathrm{MV}$, mechanical ventilation; $\mathrm{PCO}_{2}$ gap, central venous-to-arterial difference in carbon dioxide. 


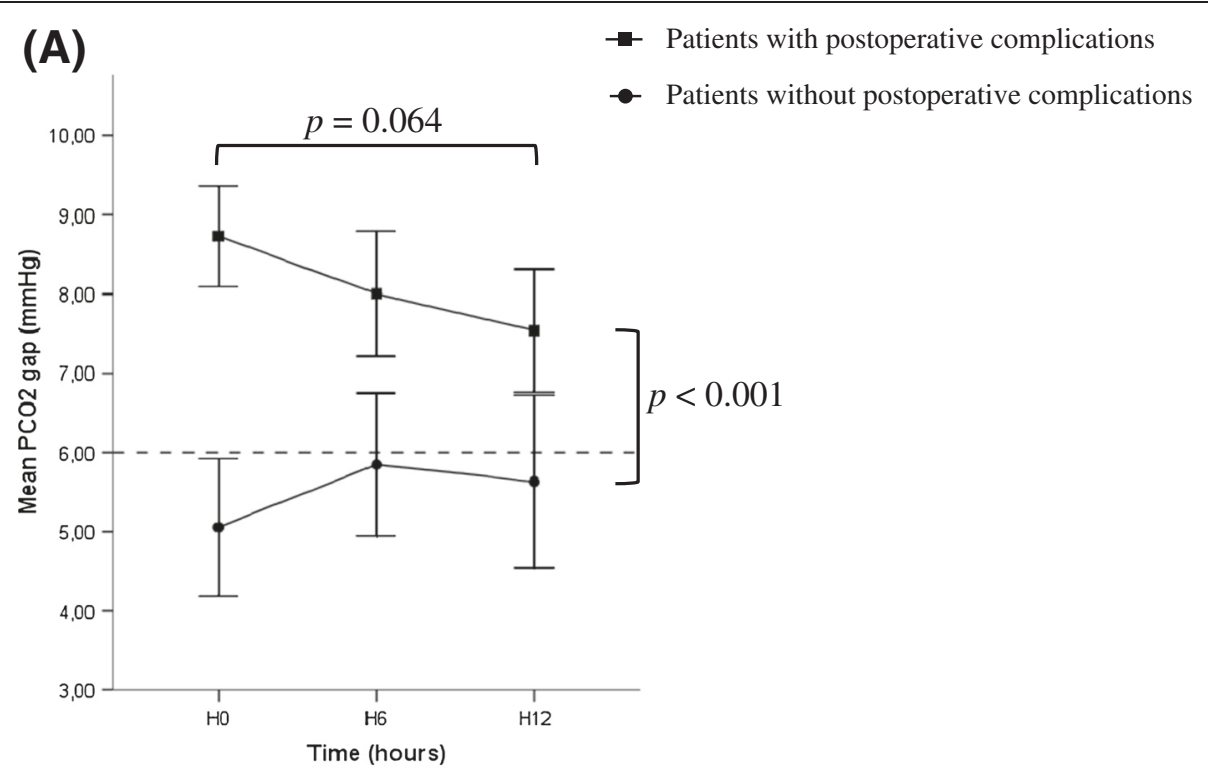

(B)

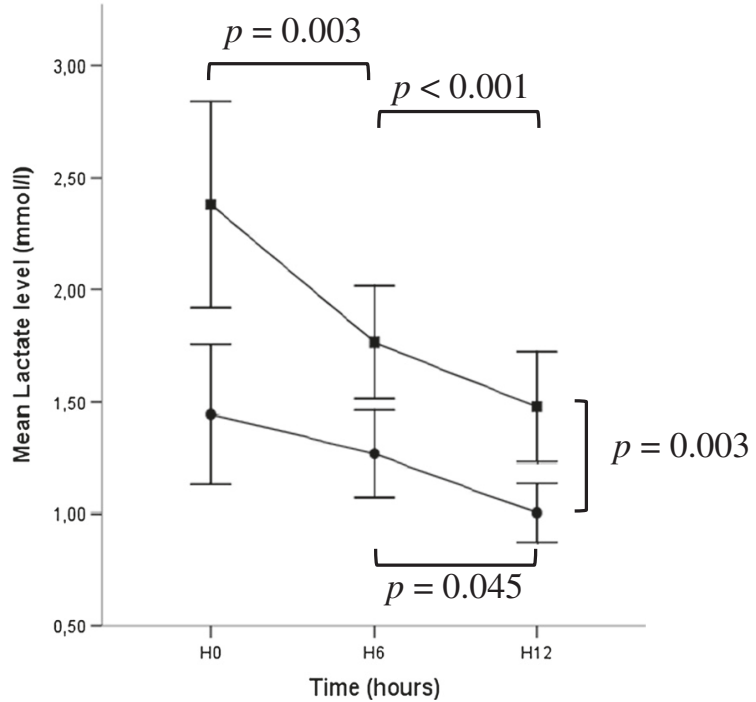

Figure 2 Trends in $\mathrm{PCO}_{2}$ gap and lactate level. (A) Trends in PCO2 gap $(\mathrm{mmHg})$ and (B) trends in lactate level $(\mathrm{mmol} / \mathrm{l})$ in patients who did $(\mathrm{n}=78$; square markers) and did not ( $\mathrm{n}=37$; circle markers) develop postoperative complications. $\mathrm{PCO}_{2}$ gap, central venous-to-arterial difference in carbon dioxide.

or high $\mathrm{ScvO}_{2}$ value does not preclude tissue hypoperfusion $[12,13,35]$. According to the modified Fick equation applied to $\mathrm{CO}_{2}$, the $\mathrm{PCO}_{2}$ gap is linearly related to $\mathrm{CO}_{2}$ production $\left(\mathrm{VCO}_{2}\right)$ and inversely related to $\mathrm{CO}$ [29]. In situations where the $\mathrm{VO}_{2} / \mathrm{DO}_{2}$ relationship is satisfied, the flow is sufficient to wash out the $\mathrm{CO}_{2}$ produced by the tissue even if there is an additional anaerobic $\mathrm{VCO}_{2}$ [22]. Conversely, when blood flow is low, the $\mathrm{PCO}_{2}$ gap may increase even if there is no increase in $\mathrm{VCO}_{2}$ [31]. Taken together, these factors may explain why, in some of our patients, the $\mathrm{PCO}_{2}$ gap was increased while $\mathrm{ScvO}_{2}$ was normal and $\mathrm{ScvO}_{2}$ failed to predict postoperative complications [36].
Similarly, lactate levels were not an independent factor associated with postoperative complications, unlike the $\mathrm{PCO}_{2}$ gap. This difference is not entirely a surprise since our surgical patients benefited from immediate hemodynamic support in the operating room and intensive care. Therefore, these patients were not necessarily in a decompensated state as evidenced by the small increase in lactate levels $(<2.5 \mathrm{mmol} / \mathrm{l}$ on average) and $\mathrm{ScvO}_{2}>70 \%$ including patients who present with postoperative complications. The increase in $\mathrm{PCO}_{2}$ gap seems only to suggest that there is a hemodynamic optimization margin for these patients. Moreover, the $\mathrm{PCO}_{2}$ gap and lactate levels may reflect different events 


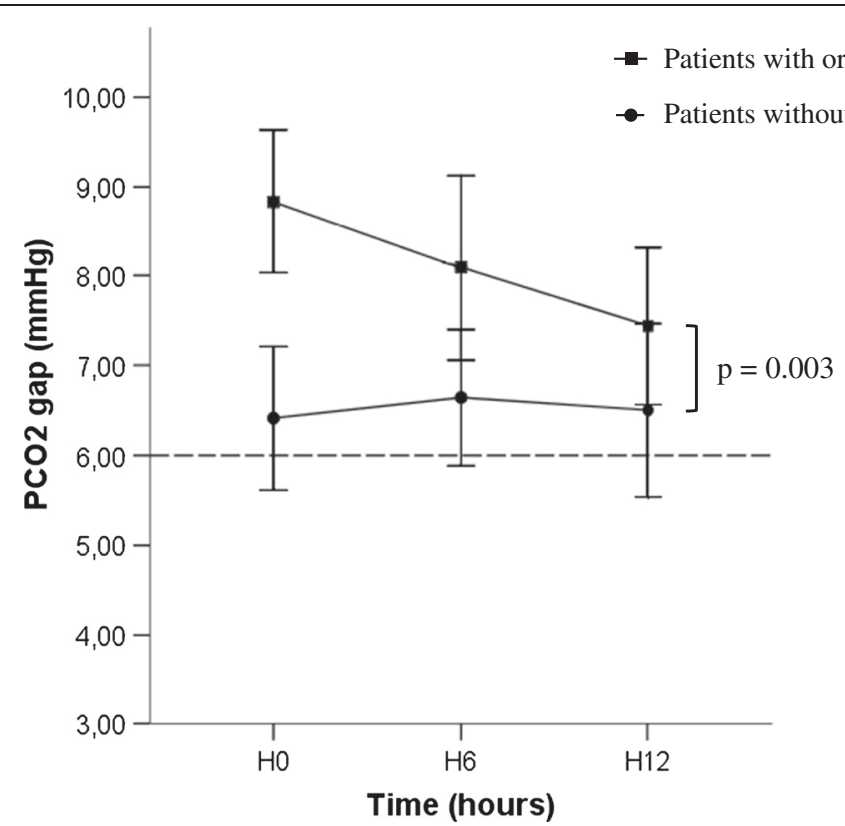

Figure 3 Trends in $\mathrm{PCO}_{2}$ gap and organ failure. Trends in $\mathrm{PCO}_{2}$ gap $(\mathrm{mmHg})$ in patients who developed organ failure ( $\mathrm{n}=54$; square markers) and those who did not ( $n=61$; circle markers). Results are expressed as means $\pm 95 \%$ confidence interval. $\mathrm{PCO}_{2}$ gap, central venous-to-arterial difference in carbon dioxide.

since lactate clearance is slower than the dynamic and rapid change in $\mathrm{PCO}_{2}$ gap; the lactate level could reflect the hemodynamic state in the last hours of surgery. If there was a significant relationship between the rate of lactate at $\mathrm{HO}$ and intraoperative variables, such as intravenous fluids, blood loss, episodes of low mean blood pressure $\leq 60 \mathrm{mmHg}$ for more than 10 minutes, and duration of surgery (data not shown), the strength of this association is quite relative, since the correlation coefficients ranged from 0.273 to 0.359 . If intraoperative events influenced the lactate levels at postoperative ICU admission, they were not the only explanation.

In this context, when early goal-directed therapy has reached its objectives including $\mathrm{ScvO}_{2}>70 \%$, the $\mathrm{PCO}_{2}$ gap could be a useful additional tool to continue processing hemodynamic optimization. In several studies using a goal-directed therapy in sepsis, it was demonstrated that either lactate clearance or $\mathrm{PCO}_{2}$ gap could be useful for identifying a persistent tissue hypoperfusion even when $\mathrm{ScvO}_{2}$ goals had been achieved [15,18]. In surgical patients, it has been shown that an individualized preload-targeted fluid loading to maintain tissue perfusion was not sufficient to prevent significant differences in outcome [37]. Interestingly, the mean $\mathrm{PCO}_{2}$ gap was larger in patients with complications with a "normalized" $\mathrm{DO}_{2} / \mathrm{VO}_{2}$ ratio $\left(\mathrm{ScvO}_{2} \geq 71 \%\right)$ than in patients without complications, with $5 \mathrm{mmHg}$ as the best threshold value. Associated with these previous studies, our results confirm that the $\mathrm{PCO}_{2}$ gap is a useful and additional tool to detect persistent tissue hypoperfusion. Moreover, the increase in lactate level, another marker of inadequate $\mathrm{VO}_{2} / \mathrm{DO}_{2}$ relationship, is often delayed compared to other markers such as $\mathrm{ScvO}_{2}$ [16]. In our study the elevation of the $\mathrm{PCO}_{2}$ gap was very early, starting at patient inclusion. Part of this increase was probably secondary to the intraoperative hemodynamic situation. The $\mathrm{PCO}_{2}$ gap at $\mathrm{HO}$ was significantly higher in patients undergoing intraoperative catecholamine $(6.88 \pm 3.16$ versus $3.02 \pm 8.7, P=0.006$ ), but this effect appears to be limited to the most seriously ill patients (those receiving catecholamines) since there was no correlation between $\mathrm{PCO}_{2}$ gap at $\mathrm{HO}$ and other intraoperative macrocirculatory variables (mean arterial pressure, heart rate, blood loss, fluid loading, blood transfusions, dieresis; data not shown).

Our study has several limitations. First, this was a single-center study involving patients undergoing major abdominal surgery. It is therefore uncertain whether our findings can be extrapolated to other non-abdominal surgery. Second, we are aware that the number of patients was relatively small which could limit the external validity of the study, and that complementary data are needed to confirm the result. Nevertheless, when we considered that one measurement of $\mathrm{PCO}_{2} \geq 6 \mathrm{mmHg}$ at inclusion was associated with the occurrence of postoperative complications, we found a post-hoc power $>90 \%$. Third, the use of central venous-to-arterial $\mathrm{PCO}_{2}$ difference as a surrogate for mixed venous $\mathrm{PCO}_{2}$ gap might be a further limitation. Nevertheless, it has been found that central venous $\mathrm{PCO}_{2}$, obtained from a simple central blood sample instead of a 
pulmonary arterial blood sample, is a valuable alternative to mixed $\mathrm{PCO}_{2}$ and that correlation with $\mathrm{CO}$ still exists in this context [38].

\section{Conclusion}

This is the first study concerning the usefulness of $\mathrm{PCO}_{2}$ gap in high-risk surgical patients at admission in postoperative ICU confirming previous results established during a surgical period or in septic patients. There is strong support for the use of goal-directed therapy, particularly for fluid resuscitation, with $\mathrm{ScvO}_{2}$ as the cornerstone of these algorithms. However, once these objectives are achieved, the $\mathrm{PCO}_{2}$ gap might be a useful and complementary tool to detect persistent tissue hypoperfusion that could be included as an additional step in the algorithms of early goal-directed therapy protocols. As the design of our study did not formally link the changes in $\mathrm{PCO} 2$ gap with tissue hypoperfusion or therapeutic change, further studies are needed to confirm these findings and be extended to other forms of surgery.

\section{Key messages}

- High $\mathrm{PCO}_{2}$ gap values were associated with a higher rate of postoperative complications in high-risk surgical patients.

- Threshold value is $6 \mathrm{mmHg}$.

- In further studies, $\mathrm{PCO}_{2}$ gap could be integrated as an additional step in the algorithms of goal-directed therapy.

\begin{abstract}
Abbreviations
$\mathrm{Cl}$ : confidence interval; $\mathrm{CO}$ : cardiac output; $\mathrm{CO}_{2}$ : carbon dioxide; $\mathrm{DO}_{2}$ : oxygen delivery; $\mathrm{H}$ : hours; $\mathrm{O}_{2}$ : oxygen; $\mathrm{PCO}_{2}$ : partial pressure of carbon dioxide; $\mathrm{PCO}_{2}$ gap: central venous-to-arterial difference in carbon dioxide; ROC: receiver operating characteristic; SAPS: Simplified Acute Physiology Score; $\mathrm{SCVO}_{2}$ : central venous oxygen saturation; SOFA: Sequential Organ Failure Assessment; $\mathrm{VCO}_{2}$ : carbon dioxide production; $\mathrm{VO}_{2}$ : oxygen consumption.
\end{abstract}

\section{Competing interests}

The authors declare that they have no competing interests.

\section{Authors' contributions}

ER was one of the designers of this study, the largest contributor to the manuscript and performed the statistical analysis. EF was one of the designers of this study and was involved in drafting the manuscript. OP participated in the design of this study, inclusion of patients and developed the database. MF was involved in the inclusion of patients, and the design and development of the database. BT was one of the designers of this study and was involved in drafting the manuscript. GL is the head of the department in which patients were included and was involved in drafting and revising the manuscript. BV was the main designer of this study and has contributed to the manuscript. All authors read and approved the manuscript.

\section{Author details}

${ }^{1}$ Department of Anaesthesiology and Intensive Care Medicine, University Hospital of Lille, Lille, France. ${ }^{2}$ Department of Anaesthesiology and Intensive Care Medicine, Hospital Estaing, University Hospital of Clermont-Ferrand, Clermont-Ferrand, France.
Received: 18 November 2014 Accepted: 13 April 2015

Published online: 13 May 2015

\section{References}

1. Gurgel ST, do Nascimento Jr P. Maintaining tissue perfusion in high-risk surgical patients: a systematic review of randomized clinical trials. Anesth Analg. 2011;112:1384-91.

2. Jhanji S, Lee C, Watson D, Hinds C, Pearse RM. Microvascular flow and tissue oxygenation after major abdominal surgery: association with post-operative complications. Intensive Care Med. 2009;35:671-7.

3. Lobo SM, Rezende E, Knibel MF, Silva NB, Paramo JA, Nacul FE, et al. Early determinants of death due to multiple organ failure after noncardiac surgery in high-risk patients. Anesth Analg. 2011;112:877-83.

4. Jhanji S, Vivian-Smith A, Lucena-Amaro S, Watson D, Hinds CJ, Pearse RM. Haemodynamic optimisation improves tissue microvascular flow and oxygenation after major surgery: a randomised controlled trial. Crit Care. 2010;14:R151.

5. Vallet B, Futier E. Perioperative oxygen therapy and oxygen utilization. Curr Opin Crit Care. 2010;16:359-64.

6. Shoemaker WC, Appel PL, Kram HB. Role of oxygen debt in the development of organ failure sepsis, and death in high-risk surgical patients. Chest. 1992;102:208-15.

7. Pearse R, Dawson D, Fawcett J, Rhodes A, Grounds RM, Bennett ED. Changes in central venous saturation after major surgery, and association with outcome. Crit Care. 2005;9:R694-9.

8. Silverman $\mathrm{HJ}$. Lack of a relationship between induced changes in oxygen consumption and changes in lactate levels. Chest. 1991;100:1012-5.

9. Dubin A, Murias G, Estenssoro E, Canales H, Badie J, Pozo M, et al. Intramucosal-arterial PCO2 gap fails to reflect intestinal dysoxia in hypoxic hypoxia. Crit Care. 2002;6:514-20.

10. Levraut J, Ciebiera JP, Chave S, Rabary O, Jambou P, Carles M, et al. Mild hyperlactatemia in stable septic patients is due to impaired lactate clearance rather than overproduction. Am J Respir Crit Care Med. 1998;157:1021-6.

11. Levy B, Mansart A, Montemont C, Gibot S, Mallie JP, Regnault V, et al. Myocardial lactate deprivation is associated with decreased cardiovascular performance, decreased myocardial energetics, and early death in endotoxic shock. Intensive Care Med. 2007;33:495-502.

12. Pope JV, Jones AE, Gaieski DF, Arnold RC, Trzeciak S, Shapiro NI. Multicenter study of central venous oxygen saturation $(\mathrm{ScvO}(2))$ as a predictor of mortality in patients with sepsis. Ann Emerg Med. 2010;55:40-6.

13. Perz S, Uhlig T, Kohl M, Bredle DL, Reinhart K, Bauer M, et al. Low and "supranormal" central venous oxygen saturation and markers of tissue hypoxia in cardiac surgery patients: a prospective observational study. Intensive Care Med. 2011:37:52-9.

14. Jansen TC, van Bommel J, Schoonderbeek FJ, Sleeswijk Visser SJ, van der Klooster JM, Lima AP, et al. Early lactate-guided therapy in intensive care unit patients: a multicenter, open-label, randomized controlled trial. Am J Respir Crit Care Med. 2010;182:752-61

15. Jones AE, Shapiro NI, Trzeciak S, Arnold RC, Claremont HA, Kline JA. Lactate clearance vs central venous oxygen saturation as goals of early sepsis therapy: a randomized clinical trial. JAMA. 2010;303:739-46.

16. Donati A, Loggi S, Preiser JC, Orsetti G, Munch C, Gabbanelli V, et al. Goal-directed intraoperative therapy reduces morbidity and length of hospital stay in high-risk surgical patients. Chest. 2007;132:1817-24.

17. Futier E, Robin E, Jabaudon M, Guerin R, Petit A, Bazin JE, et al. Central venous $\mathrm{O}(2)$ saturation and venous-to-arterial $\mathrm{CO}(2)$ difference as complementary tools for goal-directed therapy during high-risk surgery. Crit Care. 2010;14:R193.

18. Vallee F, Vallet B, Mathe O, Parraguette J, Mari A, Silva S, et al. Central venous-to-arterial carbon dioxide difference: an additional target for goal-directed therapy in septic shock? Intensive Care Med. 2008;34:2218-25.

19. Futier E, Teboul JL, Vallet B. Tissue carbon dioxide measurement as an index of perfusion: what have we missed? TACC. 2011;1:95-9.

20. Teboul JL, Mercat A, Lenique F, Berton C, Richard C. Value of the venous-arterial $\mathrm{PCO} 2$ gradient to reflect the oxygen supply to demand in humans: effects of dobutamine. Crit Care Med. 1998;26:1007-10.

21. Bakker J, Vincent JL, Gris P, Leon M, Coffernils M, Kahn RJ. Veno-arterial carbon dioxide gradient in human septic shock. Chest. 1992;101:509-15.

22. Vallet B, Teboul JL, Cain S, Curtis S. Venoarterial CO(2) difference during regional ischemic or hypoxic hypoxia. J Appl Physiol. 2000;89:1317-21. 
23. Shoemaker WC, Appel PL, Kram HB, Waxman K, Lee TS. Prospective trial of supranormal values of survivors as therapeutic goals in high-risk surgical patients. Chest. 1988;94:1176-86.

24. Le Gall JR, Lemeshow S, Saulnier F. A new Simplified Acute Physiology Score (SAPS II) based on a European/North American multicenter study. JAMA. 1993;270:2957-63.

25. Dindo D, Demartines N, Clavien PA. Classification of surgical complications: a new proposal with evaluation in a cohort of 6336 patients and results of a survey. Ann Surg. 2004;240:205-13.

26. Bennett-Guerrero E, Welsby I, Dunn TJ, Young LR, Wahl TA, Diers TL, et al. The use of a postoperative morbidity survey to evaluate patients with prolonged hospitalization after routine, moderate-risk, elective surgery. Anesth Analg. 1999;89:514-9.

27. van Beest PA, Lont MC, Holman ND, Loef B, Kuiper MA, Boerma EC. Central venous-arterial $\mathrm{pCO}(2)$ difference as a tool in resuscitation of septic patients. Intensive Care Med. 2013;39:1034-9.

28. Groeneveld AB. Interpreting the venous-arterial PCO2 difference. Crit Care Med. 1998;26:979-80

29. Lamia B, Monnet $X$, Teboul JL. Meaning of arterio-venous PCO2 difference in circulatory shock. Minerva Anestesiol. 2006;72:597-604.

30. Gutierrez G. A mathematical model of tissue-blood carbon dioxide exchange during hypoxia. Am J Respir Crit Care Med. 2004;169:525-33.

31. Neviere R, Chagnon JL, Teboul JL, Vallet B, Wattel F. Small intestine intramucosal $\mathrm{PCO}(2)$ and microvascular blood flow during hypoxic and ischemic hypoxia. Crit Care Med. 2002;30:379-84.

32. Mecher CE, Rackow EC, Astiz ME, Weil MH. Venous hypercarbia associated with severe sepsis and systemic hypoperfusion. Crit Care Med. 1990;18:585-9.

33. Collaborative Study Group on Perioperative ScvO2 Monitoring. Multicentre study on peri- and postoperative central venous oxygen saturation in high-risk surgical patients. Crit Care. 2006;10:R158.

34. Rivers E, Nguyen B, Havstad S, Ressler J, Muzzin A, Knoblich B, et al. Early goal-directed therapy in the treatment of severe sepsis and septic shock N Engl J Med. 2001;345:1368-77.

35. Textoris J, Fouché L, Wiramus S, Antonini F, Tho S, Martin C, et al. High central venous oxygen saturation in the latter stages of septic shock is associated with increased mortality. Crit Care. 2011;15:R176.

36. Shepherd SJ, Pearse RM. Role of central and mixed venous oxygen saturation measurement in perioperative care. Anesthesiology. 2009:111:649-56.

37. Futier E, Constantin JM, Petit A, Chanques G, Kwiatkowski F, Flamein R, et al. Conservative vs restrictive individualized goal-directed fluid replacement strategy in major abdominal surgery: a prospective randomized trial. Arch Surg. 2010;145:1193-200.

38. Cuschieri J, Rivers EP, Donnino MW, Katilius M, Jacobsen G, Nguyen HB, et al. Central venous-arterial carbon dioxide difference as an indicator of cardiac index. Intensive Care Med. 2005;31:818-22.

\section{Submit your next manuscript to BioMed Central and take full advantage of:}

- Convenient online submission

- Thorough peer review

- No space constraints or color figure charges

- Immediate publication on acceptance

- Inclusion in PubMed, CAS, Scopus and Google Scholar

- Research which is freely available for redistribution 